\title{
Impact of carbon nanotubes and graphene on immune cells
}

\author{
Marco Orecchioni ${ }^{1 \dagger}$, Davide Bedognetti ${ }^{2,3 \dagger}$, Francesco Sgarrella ${ }^{1}$, Francesco M Marincola ${ }^{2,3}$, Alberto Bianco $^{4^{*}}$ \\ and Lucia Gemma Delogu ${ }^{1 *}$
}

\begin{abstract}
It has been recently proposed that nanomaterials, alone or in concert with their specific biomolecular conjugates, can be used to directly modulate the immune system, therefore offering a new tool for the enhancement of immune-based therapies against infectious disease and cancer. Here, we revised the publications on the impact of functionalized carbon nanotubes (f-CNTs), graphene and carbon nanohorns on immune cells. Whereas f-CNTs are the nanomaterial most widely investigated, we noticed a progressive increase of studies focusing on graphene in the last couple of years. The majority of the works (56\%) have been carried out on macrophages, following by lymphocytes (30\% of the studies). In the case of lymphocytes, T cells were the most investigated (22\%) followed by monocytes and dendritic cells (7\%), mixed cell populations (peripheral blood mononuclear cells, 6\%), and B and natural killer (NK) cells (1\%). Most of the studies focused on toxicity and biocompatibility, while mechanistic insights on the effect of carbon nanotubes on immune cells are generally lacking. Only very recently high-throughput gene-expression analyses have shed new lights on unrecognized effects of carbon nanomaterials on the immune system. These investigations have demonstrated that some f-CNTs can directly elicitate specific inflammatory pathways. The interaction of graphene with the immune system is still at a very early stage of investigation. This comprehensive state of the art on biocompatible f-CNTs and graphene on immune cells provides a useful compass to guide future researches on immunological applications of carbon nanomaterials in medicine.
\end{abstract}

Keywords: Carbon nanotubes, Graphene, Graphene oxide, Nanomedicine, Immune system, Cells, Therapy, Diagnosis

\section{Introduction}

In the burgeoning area of nanotechnology, scientists are nowadays deeply focusing on the translational application of nanomaterials in medicine. Whereas findings from physics, genetics and immunology have already changed the everyday clinical practice in several fields, nanotechnology is expanding its legacy by implementing approaches aimed at delivering therapeutics [1-3] and developing new diagnostic imaging tools [4-6]. One of the most fascinating frontiers of nanotechnology is the development of nanomaterials for diagnostic and therapeutic

\footnotetext{
*Correspondence: a.bianco@ibmc-cnrs.unistra.fr; lgdelogu@uniss.it ${ }^{\dagger}$ Equal contributors

${ }^{4}$ Centre National de la Recherche Scientifique, Institut de Biologie Moléculaire et Cellulaire, Laboratoire d'Immunopathologie et Chimie Thérapeutique, 67000 Strasbourg, France

1 Dipartimento di Chimica e Farmacia, Università degli Studi di Sassari, 07100 Sassari, Italy

Full list of author information is available at the end of the article
}

purposes at the same time. These materials are indicated as theranostic nanomaterials or nanoparticles [7].

For any translational application of nanotechnology in medicine, a critical step is represented by the assessment of their impact on the immune system, independently of their specific purpose [8]. In fact, following parenteral administration (e.g. intravenous, intramuscular, subcutaneous, etc.), nanomaterials immediately enter in contact with peripheral immune cells either in the blood or in the peripheral tissues.

In this review, we primarily focused on the immunological impact of one of the most studied nanomaterials for biomedicine applications, namely functionalized carbon nanotubes $[9,10]$ (f-CNTs). Non functionalized (pristine) carbon nanotubes are virtually insoluble in water, tend to form intracellular conglomerates and induce considerable cytotoxicities, therefore limiting their application as diagnostic or therapeutic materials. Conversely, their 
functionalization increases the solubility in biological fluids and enhances nanotube biocompatibility. We considered CNTs as functionalized when they present on their surface any molecule covalently linked or adsorbed. Moreover, we took into consideration graphene, the new promising form of carbon [11]. Graphene is a single-layer two-dimensional sp [2] carbon nanomaterial and it has attracted tremendous attention for its intriguing physical, chemical and mechanical properties [12]. We summarized recent studies on the interaction of pristine graphene and graphene oxide (GO), with immune cells. Carbon nanohorns were also taken into consideration because they share with the above mentioned materials similar chemical characteristics. We considered the heterogeneity among the different functionalizations and described the impact on the major peripheral blood mononuclear cell (PBMC) populations: lymphocytes, monocytes and their differentiated progenies (dendritic cells and macrophages). Furthermore, we discerned lymphocyte subpopulations for each reported studies. Most relevant findings are discussed in the text. The diversity of the nanomaterials here investigated and the large area of immune-related publications make this review a useful compass in the fascinating world of immune nanotechnology. With a comprehensive state of the art on functionalized biocompatible carbon nanotubes and graphenes, we aimed at depicting a picture of their interactions with the immune system per se and in concert with their specific biomolecule conjugations.

\section{Studies selection criteria and overview}

To achieve our purpose, we performed a PubMed search using the following keywords in different combinations: functionalized carbon nanotubes, graphene, carbon nanohorns, lymphocytes, T cells, B cells, NK cells, peripheral blood mononuclear cell, dendritic cells, monocytes, macrophages, immune system and immune cells. Keyword exploration was performed one by one and as well as in several different combinations. Study lists reported include all the retrieved publications from 2005 to September 2013. High impact review articles also served as additional tool. To assess what type of cells were most investigated for their interaction with $\mathrm{f}-\mathrm{CNTs}$ and graphene we summarized the publication according to the cell type (Figure 1A).
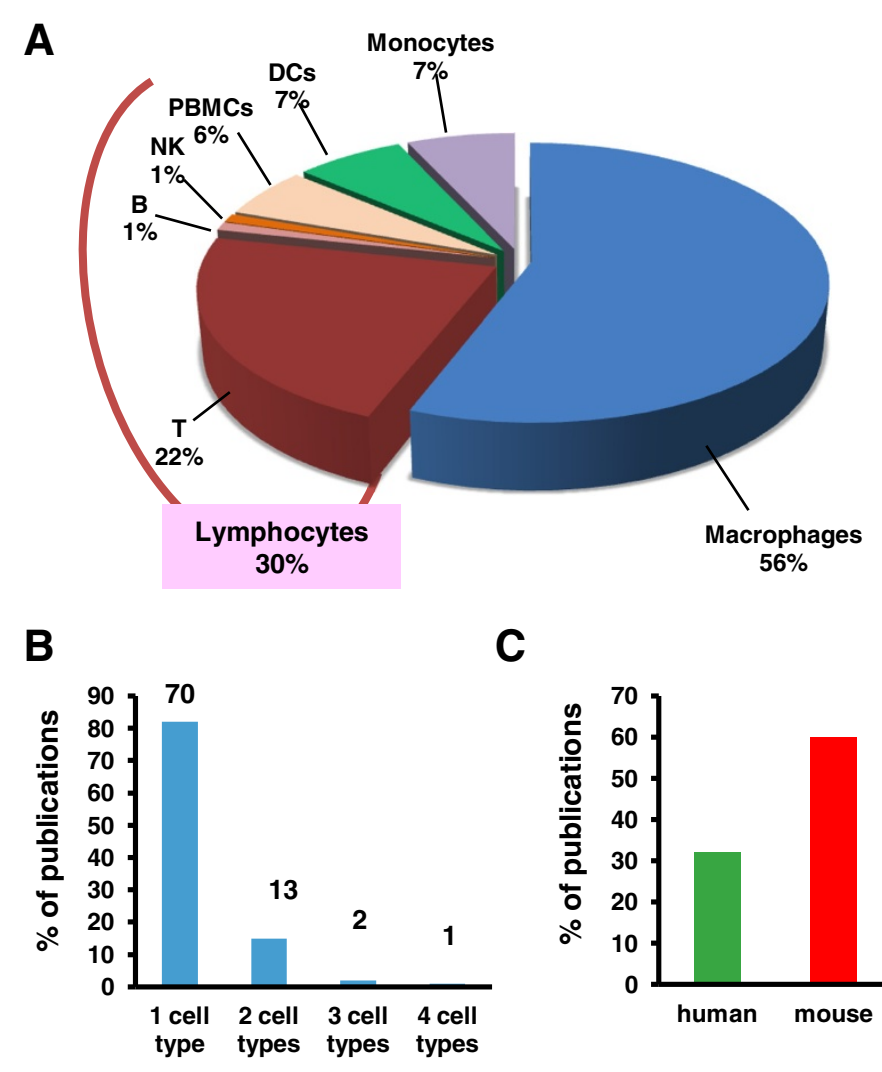

C

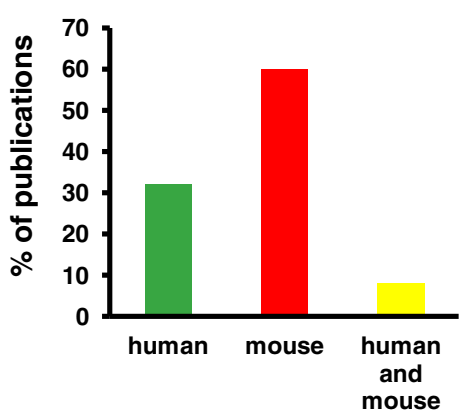

Figure 1 Overview on cells and animal models of carbon nanomaterials studies. A) Relative percentages of manuscripts carried out on different immune cell populations. B) Percentage of publications according to the number of cell population investigated; each histogram represents the exact number of publications per cell type. C) Species examined in the retrieved publications (human, mouse and combination of human and mouse). 
The majority of the works (56\%) have been carried out on macrophages probably because of their extremely important function to attack foreign invader bacteria, viruses and also foreign nanomaterials. Lymphocytes were the second biggest portion of the pie with a $30 \%$ of studies. However, we found a huge gap in the different types of lymphocyte populations. $\mathrm{T}$ lymphocytes were the most investigated (22\%) followed by the mix of cell populations (peripheral blood mononuclear cells, PBMCs), with a $6 \%$ of the studies. B cells and NK cells were less investigated with only a $1 \%$ of studies each. Studies related to the innate immune cells, others than on macrophages and NK cells, focused on monocytes (7\%) and dendritic cells (DCs; 7\%). In Figure $1 \mathrm{~B}$ we show that among 86 publications, the majority of them focused on one cell type (70) and only 1 publication looked at four different immune cell types at the same time. To our knowledge, no investigations have assessed so far on more than four immune cell populations in their interaction with $\mathrm{f}$-CNTs. In Figure $1 \mathrm{C}$ we report the number of researches conducted on humans, mice, or both, comprising to in vitro or ex vivo for human studies and in vivo in case of experiments conducted in mouse models. Even though scientists should have caution in translating their findings from mouse to human, our investigation clearly shows that the majority of the studies were conducted on mice $(60 \%), 32 \%$ in humans and very few on both $(8 \%)$. To investigate the degree of scientific interest triggered by different carbon materials, we compared f-CNTs and graphenes (pristine graphene and GO) in terms of number of publications (Figure 2A). In the last years, $\mathrm{f}-\mathrm{CNTs}$ have been extensively explored for their applications as drug carriers, targeted materials and scaffolds [9]. These works have generated a considerable quantity of ancillary data on their impact on the immune system. Graphene, which has a younger history compared to CNTs, is overall less studied. However, starting from 2012, we noticed an opposite trend, with an increasing number of studies focusing on graphene and GO, resulting in a progressive enrichment of publications dealing with this material in the last couple of years (Figure 2A). This observation reflects the growing interest for graphene among the scientific community. Carbon nanotubes have many structures, differing in length, thickness, and number of graphite layers. In Figure $2 \mathrm{~B}$ we focused on the different forms $\mathrm{f}$-CNTs categorized by their number of graphite layers: single walled (SWCNTs), double walled (DWCNTs) and multiwalled (MWCNTs). MWCNTs are the most investigated type for their interaction with immune cell (47\%), probably because their cost is lower compare to SWCNTs which have been explored in the $45 \%$ of studies. A highly useful comparison between the two types of nanotubes was performed in only a small proportion of studies (6\%).

\section{Lymphocytes}

Lymphocytes represent about 20-40\% of white blood cells (i.e., 70-90\% of PBMCs) and are responsible for the antigen-specific ( $B$ and $T$ cells) and innate (NK cells) characteristics of immune response. In Additional file 1 we summarized the studies conducted so far evaluating the impact of $\mathrm{f}-\mathrm{CNTs}$, graphenes, and carbon nanohorns in these cells [13-39]. One of the first work on CNTs, functionalized by 1,3-dipolar cycloaddition reaction and by oxidation/amidation treatment, was conducted by Dumortier et al. in 2006 [16]. The study demonstrated the non toxicity of well functionalized CNTs on primary mouse $\mathrm{T}$ and B cells. A year later, the group of Dai, while studying a specific siRNA delivery system against CXCR4
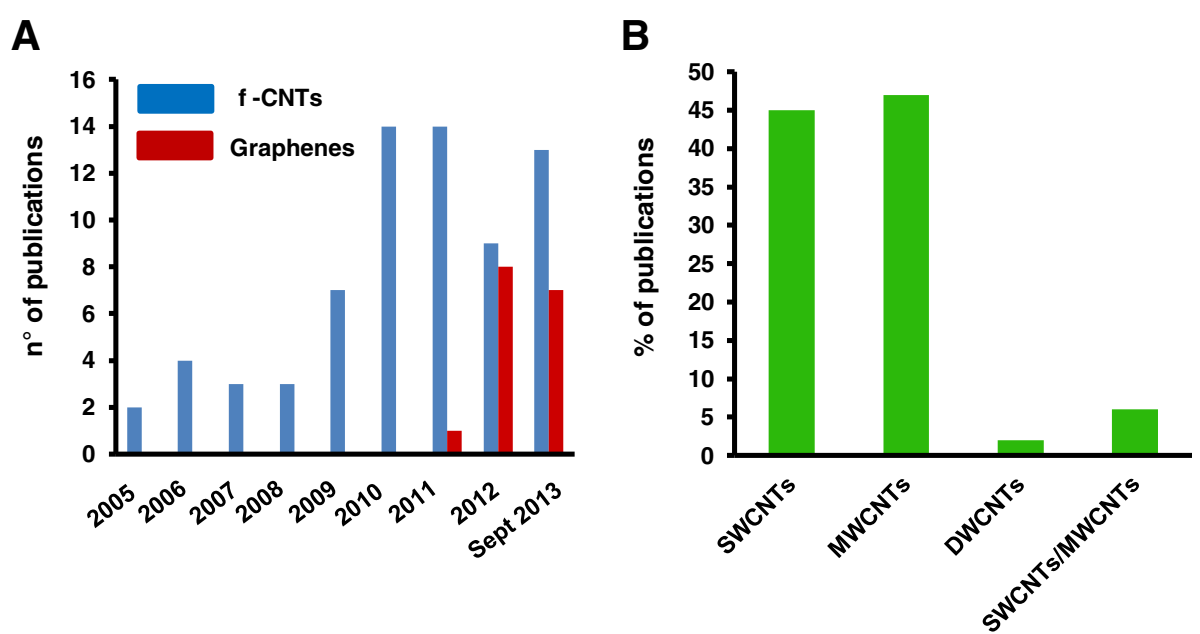

Figure 2 Status of carbon nanomaterials publications in the last $\mathbf{8}$ years. A) Analysis of the amount of publications of $\mathrm{f}$-CNTs and graphenes and their interactions with immune cells (2005 to September 2013). B) Percentage of publications based on the different kinds of f-CNTs categorized by their number of graphite layers: single-walled (SWCNTs), double-walled (DWCNTs) and multi-walled (MWCNTs). 
(a critical receptor used by HIV to infect target cells), revealed the non toxicity of pegylated CNTs on human $\mathrm{T}$ cell lines and primary T cells [17]. Delogu et al. [21] focusing on the use of CNTs for drug delivery to knockdown PTPN22, a gene related to type 1 diabetes [40], confirmed the non toxicity of PEGylated CNTs on T cells. Similar results were also found by Cato et al. [18]. A systematic genotoxic study [23] reported the effect of SWCNTs, MWCNTs, and amidated SWCNTs on cultured human lymphocytes. This investigation showed that, in contrast to non functionalized CNTs, the amidation of SWCNTs did not disturb the T cell proliferation, therefore preserving $\mathrm{T}$ cells from the observed genotoxicity. The studies discussed above highlights that different type of functionalizations such as 1,3-dipolar cycloaddition, adsorption with phospholipids and polyethylene glycol, and amidation are fundamental for preserving viability of treated cells. Furthermore, other than addressing biocompatibility issues, Fadel et al. suggested that f-CNTs can be potentially used in the context of immunotherapy [19]. They proved that anti-CD3 adsorbed onto SWNTs bundles stimulate T cell lines more effectively than equivalent concentrations of soluble anti-CD3. However, the stimuli was more efficient with functionalized versus non functionalized nanotubes [25]. The groups of Bianco and Gennaro demonstrated that two different conjugates $\mathrm{f}-\mathrm{CNTs}$ and amphotericin B can achieve an antifungal activity comparable to, or better than, amphotericin alone in T cell lines (jurkat cells) [27]. A large number of studies took advantage of the easiness of culturing cell lines such as jurkat cells [13-15,18,21,26-28,39], a line established from the peripheral blood of a 14 year old child affected by $\mathrm{T}$ cell leukemia. The clear advantages in using this cell model (highly reproducible experiments, low cost and favorable culture conditions) are somehow in contrast with its neoplastic characteristics that may not always reflect the in vivo physiological condition of T cell behavior. To avoid this concern, in a recent study, we explored the impact of different functionalized MWCNTs on PBMCs from healthy donors [31]. Two types of multi-walled carbon nanotubes (of low, $9.5 \mathrm{~nm}$, and big, 20-30 nm, diameter) were initially oxidized and further modified by 1,3-dipolar cycloaddition reaction to obtain ammonium-functionalized nanotubes. After having excluded in vitro toxicity and confirmed their dose-depending uptake, we observed that f-CNTs with smaller diameter were internalized more efficiently. Moreover, by analyzing CD4+ and CD8+ T cells, $B$ cells, NK cells, and monocytes, we surprisingly noticed that f-CNTs have a cell specific effect. In fact, none of them induced $\mathrm{T}$ cell expansion or activation (evaluated by CD25, and CD69 markers), while all of them were able to activate NK cells, which upregulated CD69 and CD161 activation markers following f-CNTs treatment. Our study [31], which was the first one exploring the impact of nanotubes on natural killer cells, suggests that the use of these f-CNTs could be explored as tool for NK expansion, for example in pre-clinical model of NK-based adoptive therapy. Similarly, the upregulation of CD25 and the production of IL- 6 by CD14+ monocytes upon treatment with ammonium-functionalized CNTsrevealed the activatory properties of these nanotubes (see discussion in the following section) on innate immune cells. Few research groups have started to look at the impact of graphene and GO on the immune system. The group of Liu showed that the complex between GO and anti-IL10 receptor antibodies elicited LPS-stimulated CD8 $\mathrm{T}$ cell responses, which makes this functionalized graphene suitable for reprogramming suppressive tumor environment in experimental models [34]. The first extensive investigation on pristine and GO to assess hemocompatibility was performed by Sasidharan et al. [35]. The authors observed a significant release of IL-8 and IL-6 in pristine graphene treated PBMC, while GO was able to determine only a moderate release of IL-8. No modulation of the other inflammatory cytokines (IL1B, IL1, TNF, and IL12) was observed. Importantly, the authors showed an excellent compatibility of both types of graphene in multiple assays assessing hemolysis, platelet aggregation and coagulation. The group of Cui addressed whether the coating of GO with polyvinylpyrrolidone (PVP) could increase biocompatibility $\mathrm{GO}$ with human immune cells, including $\mathrm{T}$ lymphocytes [38]. Besides confirming the GO dose-dependent toxicity on T cells, the authors showed that the induction of apoptosis in these cells was much less pronounced when PVP-coated GO was used [38].

\section{Monocytes}

Monocytes in the blood of healthy people are the $10-30 \%$ of PBMCs. Monocytes and their differentiated progeny (macrophages and dendritic cells) play an important role in both the innate and adaptive immunity, by exerting immune-regulatory proprieties to the production of several modulatory cytokines. These cells phagocyte material for two purposes: i) to eliminate waste, and ii) to destroy invading pathogens [41]. During a potential injection of nanomaterials for diagnostic or therapeutic purposes, monocytes will be the responsible population for a possible innate response of the immune system. It should be mentioned that different nanomaterial coating and functionalization are finalized not only to reach a good biocompatibility but also to elude phagocyticmediated clearance. In this context a good example is given by the work performed by the group of Tasciotti [42], in which the authors showed how nanoporous silicon particles coated with cellular membranes can avoid opsonization, delay uptake by mononuclear phagocytes 
and elude lysosomal pathway. However, the elicitation of monocyte functions is desirable when the purpose is to enhance the immunogenicity of a certain molecule. In Additional file 2 we report the publications related to the effects of the different carbon materials on monocytes [31,39,43-47].

One of the first works carried out on monocytes was conducted by Meunier et al. [43]. By assessing the effect of pristine double-walled CNTs on monocytes, the authors observed an induced IL-1beta secretion linked to caspase-1 and to Nlrp3 inflammasome activation in human monocytes, while no induction of the corresponding mRNA was observed. The authors also showed that similar increase of IL-1 $\beta$ was observed using oxidized DWCNTs. However, the researchers did not assess whether the IL-1beta release mediated by oxidized CNTs was dissociated from the induction of caspasemediated apoptotic stimuli. In absence of functionalization, in fact, CNTs are highly cytotoxic and can mediate the induction of several inflammatory cytokines through the activation of pathways associated to oxidative stress and caspase cascade [48]. We found, however, that MWCNTs oxidized and functionalized with ammonium group by 1,3-dipolar cycloaddition induce the expression of the CD25 activation markers and release of IL1beta, IL6, TNF, and IL10 by human monocytes not accompanied by the activation of cytotoxic mechanisms [31,39]. Recently, we provided more molecular insight into down-stream events induced by f-CNTs [39]. Through a genome-wide analysis on THP1 monocyte cell lines, we showed that ammonium-functionalized as well as oxidized MWCNTs with larger diameter provoke a profound modulation of immune-regulatory pathways not accompanied by the induction of apoptotic pathways. We demonstrated that these $\mathrm{f}-\mathrm{CNT}$ s induce profound modulation of inflammatory molecules at the transcriptomic level. Molecular pathways activated by these nanotubes include toll-like receptor (TLR), IL-6, dendritic cell maturation, TNF, NFKB, and T helper 1 chemokine pathways (CXCR3 and CCR5 ligand pathways) [39]. Because of the critical role of these inflammatory pathways (especially the $\mathrm{T}$ helper 1 chemokine pathways) in controlling immune-mediated tumor rejection, our findings suggest the highly promising application of this type of $\mathrm{f}$-CNTs as adjuvant molecules in the contest of cancer immunotherapy [49-52]. In contrast, thinner oxidized MWCNTs down-modulated genes associated with ribosomal proteins in both monocyte and $\mathrm{T}$ cell lines. GulUludag et al. [46] analyzed THP1 cells using fluorescein isothiocyanate (FITC)-labeled magnetic carbon nanotubes. Interestingly, the authors noticed an extremely high uptake of this f-CNTs into this type of cells after 1 hour, whereas localization into nucleus was observed 6 hours after their administration. A recent deep evaluation of a wide variety of $\mathrm{f}$-CNTs showed that compared to raw MWCNTs, anionic functionalization (carboxylated and PEGylated) decreased the production of cytokines/growth factors by THP1 cells (IL-1beta) or by THP1-cocultured with bronchial epithelial cell lines (PDGF-AA, TGF-beta), while neutral and low degree of CNT cationic functionalization showed intermediary effects [47]. In particular, carboxylated MWCNTs did not induce any inflammatory responses. However, high degree of CNT cationic functionalization (PEI) induced the greatest cytokine response, which was also associated to the development of pulmonary fibrosis following nasopharingeal installations in mouse models. No significant fibrosis development was observed in animals treated with anionic nanotubes. Moreover, Wang et al. [45] found that well dispersed MWCNTs by serum bovine albumin elicited a more robust IL-1beta production on THP1. Regarding graphene, studies have been focused on macrophages and dendritic cells rather than on monocytes (see following paragraphs).

\section{Macrophages}

Macrophages represent the differentiated counterpart of monocytes in the peripheral tissue. For their phagocytic characteristic and their pilot role in innate immunity, interaction between macrophages and carbon nanotubes has aroused great interest. A $56 \%$ of the studies here analyzed were carried out on this immune cell population. A possible reason of the large amount os studies is that this cell type is an easy long-term culturing primary immune cell population compare to $\mathrm{T}$ cells or natural killer cells. Additional file 3 gives an overview on the papers published in the last years on macrophage and their interaction with carbon nanotubes, carbon nanohorns, graphene and GO [16,22,29,35,38,45,47,53-103]. The large majority of the work performed in vitro was carried out using the murine macrophage cell line RAW 264.7, which can guarantee high experimental reproducibility, it is easy to culture and, being a good transfection host, it is suitable for nanomaterial-based conjugate uptake assays. Dutta et al. investigated the importance of plasma protein adsorption by oxidized SWCNTs [54] using RAW 264.7. Intriguingly, the authors noticed that the complex between SWCNT and albumin inhibited the induction of cox-2 by LPS and suggested that the proteins adsorbed onto nanotubes may alter their immune modulatory and toxicity properties. Furthermore, other modifications (e.g. non anionic surfactant coating) could reduce albumin adsorption and decreased their anti-inflammatory properties. The work of Zhou et al. [63] elucidated mechanisms of intracellular compartmentalization of functionalized SWCNTs by corroborating and expanding previous observations [55,104]. Pantarotto et al. [104] had previously shown that f-CNTs are able to cross the cell 
membrane and to accumulate into the cytoplasm or reach the nucleus of living cell, while Porter et al. [55] observed that SWCNT can cross the membrane of macrophage, localize into the lysosomes and enter the nucleus. In their work, Zhou et al. [63] studied in detail the cellular localization of SWNT surface-modified with phospholipids and polyethylene glycol (PL-PEG). The authors reported that these functionalized SWCNTs localize inside mitochondria if they cross the cell membrane or inside lysosomes when they are endocytosized. A more recent study also found similar results for carbon nanohorns that are preferentially localized into macrophage lysosomes opening future applications relying on lysosomes as target organelles for drug delivery or imaging [79]. Dong et al. [77] tested pristine SWCNTs and acidfunctionalized SWCNTs showed on RAW 264.7 that these materials could damage mitochondrial function and proteasome.

Regarding carbon nanohorns, Lacotte et al. [103] found that exposed macrophage increased the production of reactive oxygen species and pro-inflammatory cytokines. The authors suggested that a moderate level of inflammation could be exploited as an intrinsic carbon nanohorn adjuvant function for biomedical applications requiring some activation of the immune system. In the context of graphene, the number of publications related to the interaction of this material and the immune system are increasing. It has been demonstrated that pristine graphene can induce cytotoxicity on macrophage through the depletion of the mitochondrial membrane potential and the increase of intracellular reactive oxygen species [85]. Chen et al. [86] described instead the relations with GO demonstrating that it is able to simultaneously trigger autophagy and toll like receptors 4/9-regulated inflammatory responses. Moreover, the authors reported that autophagy was at least partly regulated by the toll-like receptor (TLRs) pathway. The work of Sasidharan et al. [35] gave a full picture of bio- and hemocompatibility of both pristine graphene and GO on RAW 264.7 cells and human primary blood components. All the results suggested that the toxicity of pristine graphene can be easily averted by surface modification (i.e. GO). Recently, by focusing on the effect of GO sheet lateral dimensions on human primary monocyte-derived macrophages and murine intraperitoneal macrophages, we demonstrated that the more the lateral dimensions of GO were reduced, the higher were the uptake and the impact of functionality [101]. Li et al. [99] tried to understand the interaction between graphene and cell membranes of primary human keratinocytes, human lung epithelial cells and murine macrophages. The authors showed that the entry is initiated at the asperities that are abundant along the materials making clear that local piercing initiates membrane propagation along the extended graphene edge. Overall, there are very few data present for graphene and GO keeping the door open to more mechanistic studies in vitro, ex vivo and in vivo.

\section{Dendritic cells}

Dendritic cells are specialized antigen-presenting cells that circulate in the blood - where they represent 1-2\% of PBMCs- but are preferentially found in lymphoid and peripheral organs. As showed in Figure 1A, studies performed on dendritic cells are considerable less in number as compared to those performed on other antigenpresenting cells. In Additional file 4 we summarized the publications where the authors report findings on DCs and their interaction with different materials [32,33,36,38,53,59,102]. Tkatch et al. [32] investigated in vivo and in vitro the effect of SWCNTs produced by the high-pressure CO disproportionation (HipCO nanotubes). The authors showed that this type of SWCNTs can induce pulmonary inflammation. The investigators observed that SWCNTs also facilitated the recruitment of DCs in lung tissues, while they were unable to interfere with DC activation (assessed through the measurement of CD80, CD86, CD40 and MHC class II molecules). Surprisingly, SWCNT-treated DCs suppressed T cell proliferation response. Different types of functionalization can dramatically change the recognition profile by DCs with consequent different effect on processing and antigen presentation on T cells [32]. Accordingly, the same group [59] demonstrated that coating SWCNTs with anionic phospholipids (phosphatidylserine and diacylphophatidylglycerol) can dramatically enhance their recognition and uptake by phagocytes, such DCs. The authors suggested that a phosphatidylserine coating can be utilized for targeted delivery with specified cargoes into professional phagocytes. Villa et al. [33] proved this hypothesis coating CNTs with Wilm's tumor protein 427 peptide (a vaccine tested in several clinical trials). Immunization of BALB/c mice with the SWCNT-peptide constructs, mixed with immunological adjuvants, induced specific IgG responses against the peptide, proving that CNTs are able to serve as antigen carriers for delivery into antigen presenting cells (APCs).

Data on the effect of graphene on DCs are negligible. Tkach et al. [36] showed that GO impairs the stimulatory potential of DCs by decreasing the intracellular levels of LMP7 immunoproteasome subunits required for processing of protein antigen. Polyvinylpyrrolidone (PVP) coating on GO was recently investigated [38]. The functionalization exhibited lower immunogenicity compared with pure GO in inducing differentiation and maturation. In the same work, other experiments performed on T cells and macrophages suggest that PVP-coating have a good immunological biocompatibility and immune enhancement effects ex vivo. However, no papers are present in the literature carrying out a deep toxicology analysis on 
this population. Moreover, carbon nanotube interaction has been investigated mostly in their single-walled form and no data are available for carbon nanohorns.

\section{Conclusions}

Carbon nanotubes have been investigated with great expectation by several research groups in many contexts, ranging from electronics to medicine. Through the years, however, their cytotoxic effects raised major concerns regarding the real possibility to apply carbon nanotubes in medicine as diagnostic or therapeutic applications. Pristine nanotubes in fact tend to form agglomerate, induce cellular necrosis/apoptosis and oxidative stress when ingested by phagocytes. In mice, they determine formation of granulomas, resembling in part the effect of asbestos $[48,105]$. Moreover, carbon nanotubes can directly bind some plasma protein as fibrinogen and apolipoproteins and trigger activation of complement cascade [106]. Concerning the cytotoxicity, in general, higher is the dose higher is the toxic effect. The functionalization of pristine nanotubes is clearly the key for improving their biocompatibility [107]. As described above, several studies have demonstrated that some f-CNTs bear immunostimulatory properties in absence of cytotoxicity. Importantly, most of the studies have shown lack of relevant toxicity of $\mathrm{f}-\mathrm{CNTs}$ at relatively high concentrations both in vitro and in vivo. However, several parameters as the number of walls, the diameter, the length, and, importantly, the type of functionalization can influence their cellular uptake and/or toxicity. Moreover, the route of administration is also a critical factor. For example, lung toxicity has been observed for both pristine and functionalized carbon nanotubes [108]. Toxicity of carbon nanotubes and regulatory aspects has been thoroughly revised elsewhere [109].

Graphene and GO seem to retrace the same road of scientific expectation of CNTs. Even for this material a careful assessment of toxicity in vitro and in vivo in appropriate models is necessary before starting testing in clinical trials [110]. Risk to benefit ratio needs to be accurately evaluated before any medical application i.e. as delivery tool, immunotheraphy and for biomarker detection [111-113].

Even though there are many technical advantages in using cell lines as model, more studies assessing perturbation in primary human cells are needed. Studies performed on healthy donors are carried out in most of the case separating red blood cells from PBMCs. PBMCs contain monocytes, $\mathrm{T}$ cells, B cells, NKs, and dendritic cells. A more profound evaluation of the interaction of some types of population is warranted. NKs and B cells remain very poorly investigated. Studies directed at elucidating the effects of carbon nanomaterials on specific lymphocyte or monocyte subpopulations are lacking. For example, it is totally missed the evaluation of monocyte subpopulation, as classical monocytes CD14+ CD16-, and non-classical monocytes with low level expression of CD14 and high co-expression of the CD16.For T cell studies, taking in consideration $\mathrm{T}$ regulatory cells and different stage of $\mathrm{T}$ cell maturations are desired.

Moreover, we noticed an almost absence of comparative data on many immune cell types at the same time. Looking at different cell type simultaneously would provide more insight into putative cell-type restricted effects of certain nanomaterials.

It is well known for carbon nanotubes that length and functionalization can lead to very difference reactions on cells, and it is of critical importance to differentiate carbon nanotubes in terms of physical and chemical characteristics. Learning from CNT literature, scientists should be aware to apply this state of mind also to the new born graphene, where lateral dimension and functionalization most likely can make huge difference in immune cells behaviors.

Here we showed that a considerable number of publications combining in vitro and in vivo data were carried out in mice models. Results of pre-clinical studies in mouse, however, should be taken with caution considering their profound difference in physiological immune responses compare to humans [114]. Regarding gene expression data, we found very few works employing a high throughput design. Whole genome gene-expression is able to give an overall picture of the molecular changes following experimental perturbation. This approach was carried out by Chou et al. [48] to investigate the effect of non-functionalized SWCNTs on THP1 derived macrophages using one type of nonfunctionalized nanotubes. Using the same powerful tool we recently provided a precise portrait of the molecular perturbation induced by f-CNTs on T and monocytes human cell lines [39]. As described above, we found that the main effect of MWCNTs (oxidized and further functionalized with ammonium groups) is the induction of specific inflammatory molecular pathways on monocytes, while no relevant immunologic effect on $\mathrm{T}$ cells were observed. However, functionalized MWCNTs of low diameter but lacking ammonium group were unable to induce immune activation. Rather, they determine profound modulation on genes encoding ribosomal proteins in both monocytes and $\mathrm{T}$ cells. Altogether, these results suggest that some f-CNTs bear an intrinsic immune-modulatory propriety and that this effect is cell specific. These immunemodulatory $\mathrm{f}$-CNTs emerge as potential adjuvant for immune-based therapies against infectious disease and cancer [50]. Notably, molecular pathways activated in monocytes after $\mathrm{f}$-CNT stimulation resemble somehow those that can be obtained through the activation of TLRs, which recognize pathogen-associated molecular patterns. Importantly, mononuclear phagocytes express 
much higher level of TLRs than other cells and could in part explain the inability of those $\mathrm{f}-\mathrm{CNTs}$ to induce the same profound immune-modulation on T cells. Although activation of TLRs is plausible, this mechanism has not been conclusively demonstrated yet. However, several TLRs exist, and mechanistic studies aimed at defining the molecular target of f-CNTs represent an urgent subject. In conclusion, many observations suggest that CNTs and nanohorns can exert an immune modulatory effect, but their physical molecular interaction need to be elucidated. On the other hand, the very limited amount of works available in the literature for graphene make this area of research one of the more enthusiastic challenge in the near future nanomedicine scenario.

\section{Additional files}

\section{Additional file 1: Functionalized carbon nanotubes and graphene on Lymphocytes. \\ Additional file 2: Functionalized carbon nanotubes and graphene on Monocytes. \\ Additional file 3: Functionalized carbon nanotubes and graphene on Macrophages.}

Additional file 4: Functionalized carbon nanotubes and graphene on Dendritic cells (DCs).

\section{Competing interests}

The authors declare that they have no competing interests.

\section{Authors' contributions}

$\mathrm{MO}$ carried out the bibliography search. MO, DB, FS, FMM, AB and LGD analyzed the publication data. $D B, A B$, and $L G D$ drafted the manuscript. FS and FM critically revised the manuscript and figures. All authors read and approved the final manuscript.

\section{Acknowledgements}

This work was partly supported by the Fondazione Banco di Sardegna (grant N 186/2011.0484, 2013.1308 To L.G.D.), the Sardinia Region (grant $N^{\circ}$ CRP-59720 to L.G.D.). This work was supported in part by the Intramural Research program of the U.S. National Institutes of Health (Department of Transfusion Medicine, Clinical Center) and "Gianfranco Del Prete The future: medicine, biology and nanotechnology Award" to L.G.D. A.B. wishes to thank the CNRS. L.G.D. wishes to thank the Sardinian Region for an invited professorship to A.B.

\section{Author details}

${ }^{1}$ Dipartimento di Chimica e Farmacia, Università degli Studi di Sassari, 07100 Sassari, Italy. ${ }^{2}$ Infectious Disease and Immunogenetics Section, Department of Transfusion Medicine, Clinical Center and Trans-National Institutes of Health Center for Human Immunology, National Institutes of Health, Bethesda, MD, USA. ${ }^{3}$ Research Branch, Sidra Medical and Research Center, Doha, Qatar. ${ }^{4}$ Centre National de la Recherche Scientifique, Institut de Biologie Moléculaire et Cellulaire, Laboratoire d'Immunopathologie et Chimie Thérapeutique, 67000 Strasbourg, France.

Received: 12 February 2014 Accepted: 3 April 2014

Published: 21 May 2014

\section{References}

1. Peer D, Karp JM, Hong S, Farokhzad OC, Margalit R, Langer R: Nanocarriers as an emerging platform for cancer therapy. Nat Nanotechnol 2007, 2:751-760.

2. Buxton DB: Nanomedicine for the management of lung and blood diseases. Nanomedicine (Lond) 2009, 4:331-339.
3. Jain KK: Role of nanotechnology in developing new therapies for diseases of the nervous system. Nanomedicine (Lond) 2006, 1:9-12.

4. Delogu LG, Vidili G, Venturelli E, Ménard-Moyon C, Zoroddu MA, Pilo G, Nicolussi P, Ligios C, Bedognetti D, Sgarrella F, Manetti R, Bianco A: Functionalized multiwalled carbon nanotubes as ultrasound contrast agents. Proc Natl Acad Sci U S A 2012, 109:16612-16617.

5. Hellebust A, Richards-Kortum R: Advances in molecular imaging: targeted optical contrast agents for cancer diagnostics. Nanomedicine (Lond) 2012, 7:429-445.

6. Shilo M, Reuveni T, Motiei M, Popovtzer R: Nanoparticles as computed tomography contrast agents: current status and future perspectives. Nanomedicine (Lond) 2012, 7:257-269.

7. Wang LS, Chuang MC, Ho JA: Nanotheranostics-a review of recent publications. Int J Nanomedicine 2012, 7:4679-4695.

8. Dobrovolskaia MA, Germolec DR, Weaver JL: Evaluation of nanoparticle immunotoxicity. Nat Nanotechnol 2009, 4:411-414.

9. Bianco A, Kostarelos K, Prato M: Making carbon nanotubes biocompatible and biodegradable. Chem Commun (Camb) 2011, 47:10182-10188.

10. Kostarelos K, Bianco A, Prato M: Promises, facts and challenges for carbon nanotubes in imaging and therapeutics. Nat Nanotechnol 2009, 4:627-633.

11. Bussy C, Ali-Boucetta H, Kostarelos K: Safety Considerations for Graphene: Lessons Learnt from Carbon Nanotubes. Acc Chem Res 2012, 46:692-701.

12. Geim AK, Novoselov KS: The rise of graphene. Nat Mater 2007, 6:183-191.

13. Wu W, Wieckowski S, Pastorin G, Benincasa M, Klumpp C, Briand JP, Gennaro R, Prato M, Bianco A: Targeted delivery of amphotericin B to cells by using functionalized carbon nanotubes. Angew Chem Int Ed Engl 2005, 44:6358-6362.

14. Bottini M, Bruckner S, Nika K, Bottini N, Bellucci S, Magrini A, Bergamaschi A, Mustelin T: Multi-walled carbon nanotubes induce T lymphocyte apoptosis. Toxicol Lett 2006, 160:121-126.

15. Bottini M, Cerignoli F, Dawson Ml, Magrini A, Rosato N, Mustelin T: Fulllength single-walled carbon nanotubes decorated with streptavidinconjugated quantum dots as multivalent intracellular fluorescent nanoprobes. Biomacromolecules 2006, 7:2259-2263.

16. Dumortier $H$, Lacotte $S$, Pastorin $G$, Marega $R$, Wu W, Bonifazi D, Briand JP, Prato M, Muller S, Bianco A: Functionalized carbon nanotubes are non-cytotoxic and preserve the functionality of primary immune cells. Nano Lett 2006, 6:1522-1528.

17. Liu Z, Winters M, Holodniy M, Dai H: siRNA delivery into human T cells and primary cells with carbon-nanotube transporters. Angew Chem Int Ed Engl 2007, 46:2023-2027.

18. Cato MH, D'Annibale F, Mills DM, Cerignoli F, Dawson Ml, Bergamaschi E, Bottini N, Magrini A, Bergamaschi A, Rosato N, Rickert RC, Mustelin T, Bottini M: Cell-type specific and cytoplasmic targeting of PEGylated carbon nanotube-based nanoassemblies. J Nanosci Nanotechnol 2008, 8:2259-2269.

19. Fadel TR, Steenblock ER, Stern E, Li N, Wang X, Haller GL, Pfefferle LD, Fahmy TM: Enhanced cellular activation with single walled carbon nanotube bundles presenting antibody stimuli. Nano Lett 2008, 8:2070-2076.

20. Ochoa-Olmos OE, Montero-Montoya R, Serrano-Garcia L, Basiuk EV: Genotoxic properties of nylon-6/MWNTs nanohybrid. J Nanosci Nanotechnol 2009, 9:4727-4734.

21. Delogu LG, Magrini A, Bergamaschi A, Rosato N, Dawson Ml, Bottini N, Bottini M: Conjugation of antisense oligonucleotides to PEGylated carbon nanotubes enables efficient knockdown of PTPN22 in T lymphocytes. Bioconjug Chem 2009, 20:427-431.

22. Zeinali M, Jammalan M, Ardestani SK, Mosaveri N: Immunological and cytotoxicological characterization of tuberculin purified protein derivative (PPD) conjugated to single-walled carbon nanotubes. Immunol Lett 2009, 126:48-53.

23. Cveticanin J, Joksic G, Leskovac A, Petrovic S, Sobot AV, Neskovic O: Nanotechnology 2010, 21:015102.

24. Hu X, Cook S, Wang P, Hwang HM, Liu X, Williams QL: In vitro evaluation of cytotoxicity of engineered carbon nanotubes in selected human cell lines. Sci Total Environ 2010, 408:1812-1817.

25. Fadel TR, Look M, Staffier PA, Haller GL, Pfefferle LD, Fahmy TM: Clustering of stimuli on single-walled carbon nanotube bundles enhances cellular activation. Langmuir 2010, 26:5645-5654.

26. Sabuncu AC, Kalluri BS, Qian S, Stacey MW, Beskok A: Dispersion state and toxicity of mwCNTs in cell culture medium with different T80 concentrations. Colloids Surf B Biointerfaces 2010, 78:36-43. 
27. Benincasa M, Pacor S, Wu W, Prato M, Bianco A, Gennaro R: Antifungal activity of amphotericin B conjugated to carbon nanotubes. ACS Nano 2011, 5:199-208

28. Delogu LG, Stanford SM, Santelli E, Magrini A, Bergamaschi A Motamedchaboki K, Rosato N, Mustelin T, Bottini N, Bottini M: Carbon nanotube-based nanocarriers: the importance of keeping it clean. J Nanosci Nanotechnol 2010, 10:5293-5301.

29. Kim JE, Lim HT, Minai-Tehrani A, Kwon JT, Shin JY, Woo CG, Choi M, Baek J, Jeong DH, Ha YC, Chae CH, Song KS, Ahn KH, Lee JH, Sung HJ, Yu IJ, Beck GR Jr, Cho MH: Toxicity and clearance of intratracheally administered multiwalled carbon nanotubes from murine lung. J Toxicol Environ Health A 2010, 73:1530-1543.

30. Sun Z, Liu Z, Meng J, Meng J, Duan J, Xie S, Lu X, Zhu Z, Wang C, Chen S, $\mathrm{Xu} \mathrm{H}$, Yang XD: Carbon nanotubes enhance cytotoxicity mediated by human lymphocytes in vitro. PLoS One 2011, 6:e21073.

31. Delogu LG, Venturelli E, Manetti R, Pinna GA, Carru C, Madeddu R, Murgia L, Sgarrella F, Dumortier $H$, Bianco A: Ex vivo impact of functionalized carbon nanotubes on human immune cells. Nanomedicine (Lond) 2012, 7:231-243.

32. Tkach AV, Shurin GV, Shurin MR, Kisin ER, Murray AR, Young SH, Star A, Fadeel B, Kagan VE, Shvedova AA: Direct effects of carbon nanotubes on dendritic cells induce immune suppression upon pulmonary exposure. ACS Nano 2011, 5:5755-5762

33. Villa CH, Dao T, Ahearn I, Fehrenbacher N, Casey E, Rey DA, Korontsvit T, Zakhaleva V, Batt CA, Philips MR, Scheinberg DA: Single-walled carbon nanotubes deliver peptide antigen into dendritic cells and enhance lgG responses to tumor-associated antigens. 5311 2011, 5:5300.

34. Ni G, Wang Y, Wu X, Wang X, Chen S, Liu X: Graphene oxide absorbed anti-IL10R antibodies enhance LPS induced immune responses in vitro and in vivo. Immunol Lett 2012, 148:126-132.

35. Sasidharan A, Panchakarla LS, Sadanandan AR, Ashokan A, Chandran P, Girish CM, Menon D, Nair SV, Rao CN, Koyakutty M: Hemocompatibility and macrophage response of pristine and functionalized graphene. Small 2012, 8:1251-1263.

36. Tkach AV, Yanamala N, Stanley S, Shurin MR, Shurin GV, Kisin ER, Murray AR, Pareso S, Khaliullin T, Kotchey GP, Castranova V, Mathur S, Fadeel B, Star A, Kagan VE, Shvedova AA: Graphene Oxide, But Not Fullerenes, Targets Immunoproteasomes and Suppresses Antigen Presentation by Dendritic Cells. Small 2012, 9:1686-1690.

37. Fadel TR, Li N, Shah S, Look M, Pfefferle LD, Haller GL, Justesen S, Wilson CJ, Fahmy TM: Adsorption of multimeric T cell antigens on carbon nanotubes: effect on protein structure and antigen-specific $T$ cell stimulation. Small 2013, 9:666-672.

38. Zhi X, Fang H, Bao C, Shen G, Zhang J, Wang K, Guo S, Wan T, Cui D: The immunotoxicity of graphene oxides and the effect of PVP-coating. Biomaterials 2013, 34:5254-5261.

39. Pescatori M, Bedognetti D, Venturelli E, Ménard-Moyon C, Bernardini C, Muresu E, Piana A, Maida G, Manetti R, Sgarrella F, Bianco A, Delogu LG: Functionalized carbon nanotubes as immunomodulator systems. Biomaterials 2013, 34:4395-4403.

40. Fiorillo E, Orrú V, Stanford SM, Liu Y, Salek M, Rapini N, Schenone AD, Saccucci P, Delogu LG, Angelini F, Manca Bitti ML, Schmedt C, Chan AC, Acuto O, Bottini N: Autoimmune-associated PTPN22 R620W variation reduces phosphorylation of lymphoid phosphatase on an inhibitory tyrosine residue. J Biol Chem 2010, 285:26506-26518.

41. Dale DC, Boxer L, Liles WC: The phagocytes: neutrophils and monocytes. Blood 2008, 112:935-945.

42. Parodi A, Quattrocchi N, van de Ven AL, Chiappini C, Evangelopoulos M, Martinez JO, Brown BS, Khaled SZ, Yazdi IK, Enzo MV, Isenhart L, Ferrari M, Tasciotti E: Synthetic nanoparticles functionalized with biomimetic leukocyte membranes possess cell-like functions. Nat Nanotechnol 2013, 8:61-68.

43. Meunier E, Coste A, Olagnier D, Authier H, Lefèvre L, Dardenne C, Bernad J, Béraud M, Flahaut E, Pipy B: Double-walled carbon nanotubes trigger IL-1beta release in human monocytes through Nlrp3 inflammasome activation. Nanomedicine 2012, 8:987-995.

44. Zhao D, Alizadeh D, Zhang L, Liu W, Farrukh O, Manuel E, Diamond DJ, Badie B: Carbon nanotubes enhance CpG uptake and potentiate antiglioma immunity. Clin Cancer Res 2011, 17:771-782.

45. Wang $X$, Xia T, Ntim SA, Ji Z, Lin S, Meng H, Chung $\mathrm{CH}$, George $\mathrm{S}$, Zhang $\mathrm{H}_{\text {, }}$ Wang M, Li N, Yang Y, Castranova V, Mitra S, Bonner JC, Nel AE: Dispersal state of multiwalled carbon nanotubes elicits profibrogenic cellular responses that correlate with fibrogenesis biomarkers and fibrosis in the murine lung. ACS Nano 2011, 5:9772-9787.

46. Gul-Uludag H, Lu W, Xu P, Xing J, Chen J: Efficient and rapid uptake of magnetic carbon nanotubes into human monocytic cells: implications for cell-based cancer gene therapy. Biotechnol Lett 2012, 34:989-993.

47. Li R, Wang $X$, Ji Z, Sun B, Zhang H, Chang CH, Lin S, Meng H, Liao YP, Wang M, Li Z, Hwang AA, Song TB, Xu R, Yang Y, Zink JI, Nel AE, Xia T: Surface charge and cellular processing of covalently functionalized multiwall carbon nanotubes determine pulmonary toxicity. ACS Nano 2013, 7:2352-2368.

48. Chou CC, Hsiao HY, Hong QS, Chen CH, Peng YW, Chen HW, Yang PC: Single-walled carbon nanotubes can induce pulmonary injury in mouse model. Nano Lett 2008, 8:437-445.

49. Galon J, Angell HK, Bedognetti D, Marincola FM: The continuum of cancer immunosurveillance: prognostic, predictive, and mechanistic signatures. Immunity 2013, 39:11-26.

50. Bedognetti D, Spivey TL, Zhao Y, Uccellini L, Tomei S, Dudley ME, Ascierto ML, De Giorgi V, Liu Q, Delogu LG, Sommariva M, Sertoli MR, Simon R, Wang E, Rosenberg SA, Marincola FM: CXCR3/CCR5 pathways in metastatic melanoma patients treated with adoptive therapy and interleukin-2. Br J Cancer 2013, 109:2412-2423.

51. Spivey TL, Uccellini L, Ascierto ML, Zoppoli G, De Giorgi V, Delogu LG, Engle AM, Thomas JM, Wang E, Marincola FM, Bedognetti D: Gene expression profiling in acute allograft rejection: challenging the immunologic constant of rejection hypothesis. J Trans/ Med 2011, 9:174.

52. Ascierto ML, De Giorgi V, Liu Q, Bedognetti D, Spivey TL, Murtas D, Uccellini L, Ayotte BD, Stroncek DF, Chouchane L, Manjili MH, Wang E, Marincola FM: An immunologic portrait of cancer. J Trans/ Med 2011, 9:146.

53. Yang R, Yang X, Zhang Z, Zhang Y, Wang S, Cai Z, Jia Y, Ma Y, Zheng C, Lu $Y$, Roden $R$, Chen $Y$ : Single-walled carbon nanotubes-mediated in vivo and in vitro delivery of siRNA into antigen-presenting cells. Gene Ther 2006, 13:1714-1723.

54. Dutta D, Sundaram SK, Teeguarden JG, Riley BJ, Fifield LS, Jacobs JM, Addleman SR, Kaysen GA, Moudgil BM, Weber TJ: Adsorbed proteins influence the biological activity and molecular targeting of nanomaterials. Toxicol Sci 2007, 100:303-315.

55. Porter AE, Gass M, Muller K, Skepper JN, Midgley PA, Welland M: Direct imaging of single-walled carbon nanotubes in cells. Nat Nanotechnol 2007, 2:713-717.

56. Schipper ML, Nakayama-Ratchford N, Davis CR, Kam NW, Chu P, Liu Z, Sun $X$, Dai H, Gambhir SS: A pilot toxicology study of single-walled carbon nanotubes in a small sample of mice. Nat Nanotechnol 2008, 3:216-221.

57. VanHandel M, Alizadeh D, Zhang L, Kateb B, Bronikowski M, Manohara H, Badie B: Selective uptake of multi-walled carbon nanotubes by tumor macrophages in a murine glioma model. J Neuroimmunol 2009, 208:3-9.

58. Porter AE, Gass M, Bendall JS, Muller K, Goode A, Skepper JN, Midgley PA, Welland M: Uptake of noncytotoxic acid-treated single-walled carbon nanotubes into the cytoplasm of human macrophage cells. ACS Nano 2009, 3:1485-1492.

59. Konduru NV, Tyurina YY, Feng W, Basova LV, Belikova NA, Bayir H, Clark K, Rubin M, Stolz D, Vallhov H, Scheynius A, Witasp E, Fadeel B, Kichambare PD, Star A, Kisin ER, Murray AR, Shvedova AA, Kagan VE: Phosphatidylserine targets single-walled carbon nanotubes to professional phagocytes in vitro and in vivo. PLoS One 2009, 4:e4398.

60. Antonelli A, Serafini S, Menotta M, Sfara C, Pierigé F, Giorgi L, Ambrosi G, Rossi L, Magnani M: Improved cellular uptake of functionalized singlewalled carbon nanotubes. Nanotechnology 2010, 21:425101.

61. Crinelli R, Carloni E, Menotta M, Giacomini E, Bianchi M, Ambrosi G, Giorgi L, Magnani M: Oxidized ultrashort nanotubes as carbon scaffolds for the construction of cell-penetrating NF-kappaB decoy molecules. ACS Nano 2010, 4:2791-2803.

62. Klaper R, Arndt D, Setyowati K, Chen J, Goetz F: Functionalization impacts the effects of carbon nanotubes on the immune system of rainbow trout. Oncorhynchus mykiss Aquat Toxicol 2010, 100:211-217.

63. Zhou F, Xing D, Wu B, Wu S, Ou Z, Chen WR: New insights of transmembranal mechanism and subcellular localization of noncovalently modified single-walled carbon nanotubes. Nano Lett 2010, 10:1677-1681.

64. Meng J, Yang $M$, Jia F, Xu Z, Kong H, Xu H: Immune responses of BALB/C mice to subcutaneously injected multi-walled carbon nanotubes. Nanotoxicology 2011, 5:583-591. 
65. Deng X, Xiong D, Wang Y, Chen W, Luan Q, Zhang H, Jiao Z, Wu M: Water soluble multi-walled carbon nanotubes enhance peritoneal macrophage activity in vivo. J Nanosci Nanotechnol 2010, 10:8663-8669.

66. Kagan VE, Konduru NV, Feng W, Allen BL, Conroy J, Volkov Y, Vlasova II, Belikova NA, Yanamala N, Kapralov A, Tyurina YY, Shi J, Kisin ER, Murray AR, Franks J, Stolz D, Gou P, Klein-Seetharaman J, Fadeel B, Star A, Shvedova AA Carbon nanotubes degraded by neutrophil myeloperoxidase induce less pulmonary inflammation. Nat Nanotechnol 2010, 5:354-359.

67. Montes-Fonseca SL, Orrantia-Borunda E, Aguilar-Elguezabal A, González Horta C, Talamás-Rohana P, Sánchez-Ramírez B: Cytotoxicity of functionalized carbon nanotubes in J774A macrophages. Nanomedicine 2012, 8:853-859.

68. Gao N, Zhang Q, Mu Q, Bai Y, Li L, Zhou H, Butch ER, Powell TB, Snyder SE, Jiang $G$, Yan B: Steering carbon nanotubes to scavenger receptor recognition by nanotube surface chemistry modification partially alleviates NFkappaB activation and reduces its immunotoxicity. ACS Nano 2011, 5:4581-4591.

69. Roda E, Coccini T, Acerbi D, Barni S, Vaccarone R, Manzo L: Comparative pulmonary toxicity assessment of pristine and functionalized multi-walled carbon nanotubes intratracheally instilled in rats: morphohistochemical evaluations. Histol Histopathol 2011, 26:357-367.

70. Tahara Y, Miyawaki J, Zhang M, Yang M, Waga I, lijima S, Irie H, Yudasaka M: Histological assessments for toxicity and functionalization-dependent biodistribution of carbon nanohorns. Nanotechnology 2011, 22:265106.

71. Prajapati VK, Awasthi K, Gautam S, Yadav TP, Rai M, Srivastava ON, Sundar S: Targeted killing of Leishmania donovani in vivo and in vitro with amphotericin B attached to functionalized carbon nanotubes. J Antimicrob Chemother 2011, 66:874-879.

72. Tabet L, Bussy C, Setyan A, Simon-Deckers A, Rossi MJ, Boczkowski J, Lanone S: Coating carbon nanotubes with a polystyrene-based polymer protects against pulmonary toxicity. Part Fibre Toxicol 2011, 8:3

73. Al-Jamal KT, Nerl H, Müller KH, Ali-Boucetta H, Li S, Haynes PD, Jinschek JR, Prato M, Bianco A, Kostarelos K, Porter AE: Cellular uptake mechanisms of functionalised multi-walled carbon nanotubes by 3D electron tomography imaging. Nanoscale 2011, 3:2627-2635.

74. Boncel S, Muller KH, Skepper JN, Walczak KZ, Koziol KK: Tunable chemistry and morphology of multi-wall carbon nanotubes as a route to non-toxic, theranostic systems. Biomaterials 2011, 32:7677-7686.

75. Patlolla AK, Berry A, Tchounwou PB: Study of hepatotoxicity and oxidative stress in male Swiss-Webster mice exposed to functionalized multiwalled carbon nanotubes. Mol Cell Biochem 2011, 358:189-199.

76. Kosuge H, Sherlock SP, Kitagawa T, Terashima M, Barral JK, Nishimura DG, Dai $\mathrm{H}, \mathrm{McC}$ Connell MV: FeCo/graphite nanocrystals for multi-modality imaging of experimental vascular inflammation. PLoS One 2011, 6:e14523.

77. Dong PX, Wan B, Guo LH: In vitro toxicity of acid-functionalized singlewalled carbon nanotubes: effects on murine macrophages and gene expression profiling. Nanotoxicology 2012, 6:288-303.

78. Zhang M, Zhou X, lijima S, Yudasaka M: Small-sized carbon nanohorns enabling cellular uptake control. Small 2012, 8:2524-2531.

79. Tahara Y, Nakamura M, Yang M, Zhang M, lijima S, Yudaska M: Lysosomal membrane destabilization induced by high accumulation of singlewalled carbon nanohorns in murine macrophage RAW 264.7. Biomaterials 2012, 33:2762-2769.

80. Chen T, Zang J, Wang H, Nie H, Wang X, Shen Z, Tang S, Yang J, Jia G: Water-soluble taurine-functionalized multi-walled carbon nanotubes induce less damage to mitochondria of RAW 264.7 cells. J Nanosci Nanotechnol 2012, 12:8008-8016.

81. Zhang T, Tang M, Kong L, Li H, Zhang T, Zhang S, Xue Y, Pu Y: Comparison of cytotoxic and inflammatory responses of pristine and functionalized multi-walled carbon nanotubes in RAW 264.7 mouse macrophages. J Hazard Mater 2012, 219-220:203-212.

82. Luo M, Deng X, Shen X, Dong L, Liu Y: Comparison of cytotoxicity of pristine and covalently functionalized multi-walled carbon nanotubes in RAW 264.7 macrophages. J Nanosci Nanotechnol 2012, 12:274-283.

83. Clark KA, O'Driscoll C, Cooke CA, Smith BA, Wepasnick K, Fairbrother DH, Lees PS, Bressler JP: Evaluation of the interactions between multiwalled carbon nanotubes and Caco-2 cells. J Toxicol Environ Health A 2012, 75:25-35.

84. Schinwald A, Murphy FA, Jones A, MacNee W, Donaldson K: Graphenebased nanoplatelets: a new risk to the respiratory system as a consequence of their unusual aerodynamic properties. ACS Nano 2012, 6:736-746.
85. Li Y, Liu Y, Fu Y, Wei T, Le Guyader L, Gao G, Liu RS, Chang YZ, Chen C: The triggering of apoptosis in macrophages by pristine graphene through the MAPK and TGF-beta signaling pathways. Biomaterials 2012, 33:402-411.

86. Chen GY, Yang HJ, Lu CH, Chao YC, Hwang SM, Chen CL, Lo KW, Sung LY, Luo WY, Tuan HY, Hu YC: Simultaneous induction of autophagy and toll-like receptor signaling pathways by graphene oxide. Biomaterials 2012, 33:6559-6569.

87. Yue H, Wei W, Yue Z, Wang B, Luo N, Gao Y, Ma D, Ma G, Su Z: The role of the lateral dimension of graphene oxide in the regulation of cellular responses. Biomaterials 2012, 33:4013-4021.

88. Zhou H, Zhao K, Li W, Yang N, Liu Y, Chen C, Wei T: The interactions between pristine graphene and macrophages and the production of cytokines/chemokines via TLR- and NF-kappaB-related signaling pathways. Biomaterials 2012, 33:6933-6942.

89. Rawson FJ, Yeung CL, Jackson SK, Mendes PM: Tailoring 3D single-walled carbon nanotubes anchored to indium tin oxide for natural cellular uptake and intracellular sensing. Nano Lett 2013, 13:1-8.

90. Matesanz MC, Vila M, Feito MJ, Linares J, Gonçalves G, Vallet-Regi M, Marques PA, Portolés MT: The effects of graphene oxide nanosheets localized on F-actin filaments on cell-cycle alterations. Biomaterials 2013, 34:1562-1569.

91. Yang M, Wada M, Zhang M, Kostarelos K, Yuge R, lijima S, Masuda M, Yudasaka M: A high poly(ethylene glycol) density on graphene nanomaterials reduces the detachment of lipid-poly(ethylene glycol) and macrophage uptake. Acta Biomater 2013, 9:4744-4753.

92. Hamilton RF Jr, Xiang C, Li M, Ka I, Yang F, Ma D, Porter DW, Wu N, Holian A: Purification and sidewall functionalization of multiwalled carbon nanotubes and resulting bioactivity in two macrophage models. Inhal Toxicol 2013, 25:199-210.

93. Girish CM, Sasidharan A, Gowd GS, Nair S, Koyakutty M: Confocal Raman Imaging Study Showing Macrophage Mediated Biodegradation of Graphene In Vivo. Adv Healthc Mater 2013, 2:1489-1500.

94. Dvash R, Khatchatouriants A, Solmesky LJ, Wibroe PP, Weil M, Moghimi SM Peer D: Structural profiling and biological performance of phospholipidhyaluronan functionalized single-walled carbon nanotubes. J Control Release 2013, 170:295-305.

95. Wan B, Wang ZX, Lv QY, Dong PX, Zhao LX, Yang Y, Guo LH: Single-walled carbon nanotubes and graphene oxides induce autophagosome accumulation and lysosome impairment in primarily cultured murine peritoneal macrophages. Toxicol Lett 2013, 221:118-127.

96. Jiang $Y$, Zhang $H$, Wang $Y$, Chen $M$, Ye S, Hou Z, Ren L: Modulation of apoptotic pathways of macrophages by surface-functionalized multi-walled carbon nanotubes. PLoS One 2013, 8:e65756.

97. Qu G, Liu S, Zhang S, Wang L, Wang X, Sun B, Yin N, Gao X, Xia T, Chen J, Jiang GB: Graphene oxide induces toll-like receptor 4 (TLR4)-dependent necrosis in macrophages. ACS Nano 2013, 7:5732-5745.

98. Villegas JC, Alvarez-Montes L, Rodríguez-Fernández L, González J, Valiente R, Fanarraga ML: Multiwalled Carbon Nanotubes Hinder Microglia Function Interfering with Cell Migration and Phagocytosis. Adv Healthc Mater 2013, 3:424-432.

99. Li Y, Yuan H, von dem Bussche A, Creighton M, Hurt RH, Kane AB, Gao H: Graphene microsheets enter cells through spontaneous membrane penetration at edge asperities and corner sites. Proc Natl Acad Sci U S A 2013, 110:12295-12300.

100. Kotagiri N, Lee JS, Kim JW: Selective pathogen targeting and macrophage evading carbon nanotubes through dextran sulfate coating and PEGylation for photothermal theranostics. J Biomed Nanotechnol 2013, 9:1008-1016.

101. Russier J, Treossi E, Scarsi A, Perrozzi F, Dumortier H, Ottaviano L, Meneghetti M, Palermo V, Bianco A: Evidencing the mask effect of graphene oxide: a comparative study on primary human and murine phagocytic cells. Nanoscale 2013, 5:11234-11247.

102. Yang M, Flavin K, Kopf I, Radics G, Hearnden CH, McManus GJ, Moran B, Villalta-Cerdas A, Echegoyen LA, Giordani S, Lavelle EC: Functionalization of Carbon Nanoparticles Modulates Inflammatory Cell Recruitment and NLRP3 Inflammasome Activation. Small 2013, 9:4194-4206.

103. Lacotte S, García A, Décossas M, Al-Jamal WT, Li S, Kostarelos K, Muller S, Prato M, Dumortier H, Alberto B: Interfacing Functionalized Carbon Nanohorns with Primary Phagocytic Cells. Adv Materials 2008, 20:2421-2426.

104. Pantarotto D, Briand JP, Prato M, Bianco A: Translocation of bioactive peptides across cell membranes by carbon nanotubes. Chem Commun (Camb) 2004, 16:17. 
105. Poland CA, Duffin R, Kinloch I, Maynard A, Wallace WA, Seaton A, Stone V, Brown S, Macnee W, Donaldson K: Carbon nanotubes introduced into the abdominal cavity of mice show asbestos-like pathogenicity in a pilot study. Nat Nanotechnol 2008, 3:423-428.

106. Salvador-Morales C, Flahaut E, Sim E, Sloan J, Green ML, Sim RB: Complement activation and protein adsorption by carbon nanotubes. Mol Immunol 2006, 43:193-201.

107. Ali-Boucetta HN, Sainz R, Herrero MA, Tian B, Prato M, Bianco A, Kostarelos $\mathrm{K}$ : Asbestos-like pathogenicity of long carbon nanotubes alleviated by chemical functionalization. Angew Chem Int Ed 2013, 52:2274-2278.

108. Coccini T, Manzo L, Roda E: Safety evaluation of engineered nanomaterials for health risk assessment: an experimental tiered testing approach using pristine and functionalized carbon nanotubes. ISRN Toxicol 2013, 2013:825427.

109. Beg S, Rizwan M, Sheikh AM, Hasnain MS, Anwer K, Kohli K: Advancement in carbon nanotubes: basics, biomedical applications and toxicity J Pharm Pharmacol 2011, 63:141-163.

110. Bianco A: Graphene: safe or toxic? The two faces of the medal. Angew Chem Int Ed Engl 2013, 52:4986-4997.

111. Gottardi R, Douradinha B: Carbon nanotubes as a novel tool for vaccination against infectious diseases and cancer. J Nanobiotechnology 2013, 11:30.

112. Tomei S, Wang E, Delogu LG, Marincola FM, Bedognetti D: Non-BRAFtargeted therapy, immunotherapy, and combination therapy for melanoma. Expert Opin Biol Ther 2014, 14:663-686.

113. Bedognetti D, Balwit JM, Wang E, Disis ML, Britten CM, Delogu LG, Tomei S, Fox BA, Gajewski TF, Marincola FM, Butterfield LH: SITC/iSBTc Cancer Immunotherapy Biomarkers Resource Document: online resources and useful tools - a compass in the land of biomarker discovery. J Trans/ Med 2011, 9:155

114. Shay T, Jojic V, Zuk O, Rothamel K, Puyraimond-Zemmour D, Feng T, Wakamatsu E, Benoist C, Koller D, Regev A: Conservation and divergence in the transcriptional programs of the human and mouse immune systems. Proc Natl Acad Sci U S A 2013, 110:2946-2951.

doi:10.1186/1479-5876-12-138

Cite this article as: Orecchioni et al:: Impact of carbon nanotubes and graphene on immune cells. Journal of Translational Medicine 2014 12:138.

\section{Submit your next manuscript to BioMed Central and take full advantage of:}

- Convenient online submission

- Thorough peer review

- No space constraints or color figure charges

- Immediate publication on acceptance

- Inclusion in PubMed, CAS, Scopus and Google Scholar

- Research which is freely available for redistribution 